\title{
Agentes comunitários de saúde: a reconstrução do conceito de risco no nível local
}

Vera Joana Bornstein ${ }^{1}$

Helena Maria Scherlowski Leal David² José Wellington Gomes de Araújo³

BORNSTEIN, V.J.; DAVID, H.M.S.L.; ARAÚJO, J.W.G. Community health agents: reconstruction of the risk concept at local level. Interface - Comunic., Saude, Educ., v.14, n.32, p.93-101, jan./mar. 2010.

The risk concept and its limits are discussed as a technical-scientific construct for representing reality and as a support device for social intervention. The historical evolution of epidemiology and the risk concept is related to the idea of social arbitration among population groups. The possibility of appropriating this concept for expanding perceptions and strengthening social responses to life and health situations is examined in the light of pedagogical experience based on the perspective of popular health education using community health agents in a peripheral urban locality. It is argued that participatory educational processes increase the sharing of knowledge and the capacity to critically analyze the multiple relationships between health problems and local-general contexts of life. The issue of social arbitration in response to limiting situations is brought out again.

Keywords: Community health agents. Concept formation. Health education. Risk.
Discute-se o conceito de risco e seus limites como constructo técnico-científico de representação da realidade e dispositivo de apoio à intervenção social. A evolução histórica da epidemiologia e do conceito de risco é relacionada à ideia de arbitragem social junto aos grupos populacionais, examinando-se a possibilidade de apropriação desse conceito para a ampliação da percepção e o fortalecimento das respostas sociais às situações de saúde e vida, à luz de uma experiência pedagógica baseada na perspectiva da educação popular e saúde, com agentes comunitários de saúde de uma localidade urbana periférica. Defende-se que os processos educativos participativos ampliam o compartilhamento de saberes e a capacidade de analisar criticamente as múltiplas relações entre os problemas de saúde e os contextos de vida local e global, recolocando a questão da arbitragem social nas respostas às situações-limite.

Palavras-chave: Agentes comunitários de saúde. Formação de conceito. Educação em saúde. Risco.
1 Escola Politécnica de Saúde Joaquim Venâncio, Fundação Oswaldo Cruz (Fiocruz). Av. Brasil 4365, sala 311, Rio de Janeiro - RJ, Brasil. 21040-900. vejoana@fiocruz.br ${ }^{2}$ Departamento de Enfermagem de Saúde Pública, Faculdade de Enfermagem,

Universidade do Estado do Rio de Janeiro (UERJ)

${ }^{3}$ Escola Nacional de

Saúde Pública Sergio Arouca, Fiocruz. 


\section{Introdução}

O agente comunitário de saúde (ACS) ocupa posição singular e contraditória no trabalho em saúde na atenção básica: por um lado, é membro da comunidade-alvo e, como tal, também usuário dos serviços públicos de saúde; portanto, conhece e enfrenta, como membro da classe trabalhadora, as mesmas dificuldades de acesso e de resolutividade que perpassam o sistema público de saúde. Por outro, torna-se integrante, nem sempre legitimado, de uma equipe de saúde cujo processo de trabalho tende a reproduzir, de forma igualmente contraditória, a divisão social do trabalho e as disputas em torno dos projetos terapêuticos (Nunes, 1998; Merhy, 1997). Com seu processo de profissionalização marcado pelo debate ideológico e político, o ACS constitui-se hoje em força de trabalho expressiva, com mais de duzentos mil profissionais atuando em todo o país.

Entre as atribuições específicas dos ACS, estabelecidas na portaria n. 648, Anexo I (Brasil, 2006), consta o desenvolvimento de atividades classificadas como de promoção da saúde, prevenção de doenças e agravos, e vigilância à saúde. Dentre as ações citadas, estão visitas domiciliares e ações individuais e coletivas tanto nos domicílios como na comunidade. Há um destaque para a recomendação de que o ACS mantenha a equipe de saúde informada sobre as famílias, "principalmente a respeito daquelas em situação de risco" (p.71).

No que tange à formação, o referencial curricular nacional do Curso Técnico de Agente Comunitário de Saúde elaborado pelo Ministério da Educação e pelo Ministério da Saúde, em 2004, prevê um itinerário formativo composto por três etapas, sendo que, na terceira, o "desenvolvimento de competências no âmbito da promoção, prevenção e monitoramento das situações de risco ambiental e sanitário" constitui seu eixo central (Brasil, 2004, p.21).

Estes documentos destacam a importância do conceito de risco, referindo-se a fatores e situações de risco como um dos componentes fundamentais no processo de trabalho a ser realizado pelos ACS, cuja ênfase é dirigida à prevenção de doenças, ao controle de sua transmissão e/ou ao seu agravamento, a fatores ambientais e aos chamados riscos sociais - que são listados: pobreza, violência, migrações, entre outros. Não há explicação ou discussão sobre o conceito de risco.

A definição de fator de risco que norteia o trabalho desses agentes é, de modo geral, preestabelecida pelas instituições de saúde, e reflete uma forte influência do modelo ecológico, que remete aos elos da cadeia epidemiológica, com foco na causalidade por um agente biológico, ou do modelo socioecológico, que passa a incluir os fatores comportamentais e relativos aos hábitos individuais (Nunes, 1998). Esta orientação manifesta-se na composição dos dados colhidos pelo Sistema de Informação da Atenção Básica (SIAB), cujo destaque recai sobre a informação vinculada às diretrizes programáticas do Ministério da Saúde. No nível local, o desdobramento desta concepção é a exigência de preenchimento das fichas para acompanhamento domiciliar de gestantes, hipertensos, diabéticos, tuberculosos e hansenianos, assim como de crianças.

Este artigo discute o conceito de risco, problematizando seu limite como constructo técnicocientífico de representação da realidade e como dispositivo de apoio à intervenção social, contrapondo-o à organização do processo de trabalho em saúde com base em metodologias pedagógicas participativas, a partir das situações de vida e dos processos saúde-doença da população local. Apoia-se em uma experiência pedagógica desenvolvida com ACS na Unidade Básica de Saúde da Vila do João, Complexo da Maré, Rio de Janeiro, em 2002.

Inicia-se com uma revisão sobre o conceito de risco como instrumento para a arbitragem social (Mitjavila, 2002), passando ao relato da construção coletiva do conceito de risco tomando, como eixo, o trabalho cotidiano das ACS e a problematização das condições de vida e saúde no local. Nas conclusões, são debatidos alguns princípios pedagógicos referentes à educação popular e saúde (EP\&S), como perspectiva capaz de contribuir nos processos participativos para a construção de diagnósticos comunitários de saúde (Stotz et al., 2005). 


\section{O conceito de risco e as mudanças na arbitragem social}

Os valores positivos associados à saúde, a higidez e a longevidade, parecem ser os mais pujantes da contemporaneidade. Talvez signifiquem a atualização do mito da imortalidade ou, pelo menos, a possibilidade de uma morte retardada, indefinida (Araújo, 2004).

A disparidade nas condições de vida entre os diversos grupos da população discrimina o acesso aos bens que proporcionam a saúde. Nesse caso, pode-se dizer que Hygeia (entre os gregos antigos, mantenedora da saúde, da higidez) seria a deusa da saúde para os aquinhoados, enquanto Panacéia (que recupera a saúde) seria a deusa dos despossuídos. Em todo caso, se é verdade que a higidez e a longevidade são valores efetivamente positivos, eles só podem ser alcançados mediante um duro programa que objetiva, a todo custo, driblar os riscos prementes e permanentes de adoecer e de morrer, conferindo ao conceito de risco uma valoração claramente negativa.

Deborah Lupton (1999) refere-se a mudanças no significado de risco que se deram a partir do século XVII, sobretudo no XVIII, com o desenvolvimento da ciência e do pensamento racional, o qual supõe que o mundo social e natural segue leis que podem ser medidas, calculadas e, portanto, previstas. Por volta do século XIX, a noção de risco teria sido ampliada, abrangendo não só os fatores ligados à natureza, mas também os relacionados ao ser humano, presentes na sua conduta, na sua liberdade, nas suas relações e na própria sociedade.

No campo da saúde, o risco é um conceito probabilístico, oriundo e sustentado pela assim denominada epidemiologia moderna. De acordo com a lógica inferencial da estatística, as probabilidades contêm, necessariamente, um princípio de incerteza, de tal forma que nenhum resultado pode ser atribuído a um indivíduo em particular, senão ao grupo ao qual pertence. Outra consideração é a de que certo risco epidemiológico pode ser maior ou menor para determinado grupo ou situação. Isso implica que um risco pode ter uma probabilidade baixa ou remota: pode até ser possível (no sentido de que tudo é, em tese, possível), mas não ser plausível. Na divulgação desse conceito, sobretudo pelos meios de comunicação de massa, foi inevitável a polissemia com a noção de risco presente no senso comum (Araújo, 2004).

Nas sociedades ocidentais contemporâneas, a noção de risco e de arriscado é comumente usada tanto no discurso popular como no discurso técnico. No que se refere ao entendimento popular, a noção de risco tende a ser usada para se referir a ameaça, perigo, prejuízo, e com a conotação de algo mais negativo do que propriamente desastroso. No discurso técnico, são usadas expressões como análise de risco, avaliação de risco e administração de risco, em áreas como medicina e saúde pública, finanças, direito, negócios e indústria (Lupton, 1999).

A noção de risco difundida pela educação sanitária e pelos meios de comunicação costuma trazer, de forma implícita ou explícita, a ideia da culpabilização dos indivíduos pelos seus males presentes ou futuros (Valla, 1993). A epidemiologia - de onde emana essa noção - teve seu nascedouro na Inglaterra, em plena era vitoriana. Dessa forma, a disciplina seria perpassada pelos valores do puritanismo anglo-saxão, sendo a epidemiologia dos fatores de risco a atualização científica daqueles valores. Para contornar os fatores de risco, que estão todo o tempo em todo lugar, seria necessário uma severa e continuada educação dos prazeres (Castiel, 1998).

Mas a ideia de risco não é uma invenção epidemiológica, evidentemente. Segundo Mitjavila (2002), o risco é uma construção móvel, passível de circulação abrangente em termos de código para os perigos e ameaças que caracterizam a vida nas sociedades contemporâneas. Construção social relacionada de forma complexa com o conhecimento tecnocientífico, é, portanto, um dispositivo de conhecimento e poder, instrumento de arbitragem para os problemas sociais. Para Lupton (1999), o conceito de risco ganhou importância ultimamente devido ao aumento da influência das decisões com relação ao futuro da sociedade. O efeito paradoxal é que, na busca por controlar o risco, conhece-se, cada vez mais, a imprevisibilidade.

A importância do risco como recurso para a arbitragem social, na medida em que diversos agentes institucionais necessitam tomar decisões que, muitas vezes, apresentam-se como alternativas dicotômicas, é abordada por Mitjavila (2002, p.130): 
Sem ser o único mecanismo envolvido, o risco parece permear cada vez com maior força os discursos e as práticas que agem no coração de muitas das circunstâncias de arbitragem social. Cada vez mais decisões de tipo arbitral parecem ser tomadas em nome da exposição a algum tipo de risco ou riscos que afetam tanto os indivíduos como as organizações [...].

No entanto, o risco como recurso para a arbitragem social pode refletir uma leitura parcial da situação social, já que atribui a causa dos problemas a algumas variáveis, geralmente limitadas pela busca do fator principal de risco. No setor saúde, essas variáveis costumam ser aquelas passíveis de intervenção médica, contrapondo, assim, a racionalidade científica (Bachelard, 1985) às concretas condições de produção da vida e da saúde.

Enquanto dispositivo biopolítico, o risco pode ser consentâneo com novas formas de exclusão social, não redutíveis às categorias clássicas de dominação e exploração. Seu discurso não nega as desigualdades sociais, mas estas são frequentemente redefinidas no sentido da individualização dos riscos sociais. Então, "exige-se dos indivíduos mais desestabilizados que ajam como sujeitos autônomos" (Mitjavila, 2002, p.136). As políticas de integração são substituídas por políticas de inserção. Nesse caso, o risco é o principal fundamento para a provisão seletiva de serviços sociais.

Direcionada aos setores em situação de miséria, a focalização é uma das funções arbitrais do risco. Mas o risco não é um recurso que se presta apenas à arbitragem social da miséria focalizada. Vivemos em uma sociedade de riscos, e essa noção/conceito perpassa todas as atividades humanas, das operações financeiras ao ato de atravessar a rua (Caponi, 2003; Lupton, 1999).

No nível das microrrelações, o risco passa a fazer parte da identidade dos indivíduos, uma vez que se mencionam os estilos de vida como seu locus privilegiado (Castiel, 1998). No nível macrossocial, são apontadas críticas às abordagens parciais do problema (Santos, 1979), quando se atribui a "crise urbana" a fatores como explosão demográfica, êxodo rural ou, ainda, ao subemprego, selecionando aspectos da realidade como se existissem setores autônomos na sociedade e esquecendo, portanto, de analisar suas interdependências. Da mesma forma, ao se focalizarem determinados grupos e categorias, individualizam-se os riscos sociais, e, ao se perceberem os problemas sociais em função de disposições psicológicas e familiares, acaba-se por limitar a análise da situação de conjunto e de sua dinâmica (Araújo, 2004).

Um reflexo deste enfoque relacionado ao grupo familiar é abordado por Eymard Vasconcelos (1999, p. 11), que se refere aos estudos e publicações sobre a família brasileira e aos trabalhos sociais direcionados a ela, onde se ressalta a existência de algumas famílias nas classes populares que vivem situações especiais de risco e que, por isso, necessitam atenção diferenciada do Estado para, de certa forma, "garantir" os direitos de cidadania.

Telles (2001, p.158) refere-se ao caráter compensatório e ao perfil seletivo e focalizado desse tipo de programa social, substituindo, frequentemente, a produção de direitos pelo atendimento de "necessidades".

O enfoque do risco como dispositivo arbitral para a provisão de serviços pode, portanto, deslocar a análise da situação e dos problemas existentes para a análise daquilo que tem probabilidade de acontecer, no futuro. São priorizadas as situações que podem vir a causar problemas, em detrimento das necessidades, direitos ou demandas presentes e imediatamente observáveis (Araújo, 2004). Ainda assim, Mitjavila (2002) reconhece a importância de se identificarem os perigos e incertezas da vida, como forma de organizar a percepção e as respostas sociais perante esses riscos, entendidos como situações-limite diante da vida que produzem esforços pela superação de determinada realidade (Freire, 1970). Este é o foco principal na perspectiva da educação popular e saúde, que tentamos desenvolver a seguir.

\section{A construção do conceito de risco com ACS no nível local}

A experiência que apoia esta discussão foi desenvolvida em 2002, em um projeto de integração ensino-serviço-pesquisa do qual participaram o Posto de Saúde da Vila do João, o Departamento de 
Enfermagem de Saúde Pública da Faculdade de Enfermagem da Universidade do Estado do Rio de Janeiro (UERJ) e o Núcleo de Estudos Locais em Saúde (Elos) da Fundação Oswaldo Cruz (Fiocruz).

O Posto de Saúde da Vila do João está vinculado à Área Programática 3.1 (AP 3.1.) da Secretaria Municipal de Saúde do Rio de Janeiro (SMS-RJ), que é uma das áreas de mais alta densidade demográfica do município. A Vila do João fica no Complexo da Maré, $30^{\circ}$ Região Administrativa, e a população adscrita a esta unidade de saúde era de aproximadamente vinte mil habitantes.

No começo da década de 1980, o Posto de Saúde da Vila do João era vinculado à Universidade Federal do Rio de Janeiro (UFRJ), e foi fechado no início da década de 1990 devido a incidentes de violência que ocorreram no local. Em 1998, a unidade de saúde foi reativada, com a contratação de uma equipe constituída por uma enfermeira, uma assistente social e 13 agentes de saúde. A partir de novembro de 1998, foram feitos: o levantamento da história e o mapeamento da comunidade, o cadastramento das famílias, visitas domiciliares de rotina, acompanhamento das famílias em situação de risco e trabalho educativo nas instituições locais, tais como escolas e creches.

Inicialmente, as ACS realizavam o cadastramento das famílias de suas microáreas em formulários próprios da Área Programática 3.1. Em folhas anexas, registravam livremente as informações relevantes e as observações realizadas durante as visitas domiciliares. Com a perspectiva de oficialização do Programa de Agentes Comunitários de Saúde (PACS) em 2001, foi feito o recadastramento das famílias da área, e introduzida a Ficha $A$ do Sistema de Informação de Atenção Básica (SIAB), que substituiria o formulário utilizado anteriormente.

Nas várias oportunidades de formação promovidas pela equipe local, havia sido enfatizado o conceito amplo de saúde e a importância das múltiplas determinações do processo saúde-doença. Havia também a orientação de que, nas visitas domiciliares, os ACS fizessem o registro de observações que servissem de subsídio para toda a equipe no acompanhamento da população. Nesse sentido, as agentes faziam o relato da sua percepção sobre as condições e modos de vida da população, as dificuldades encontradas e, inclusive, a satisfação em relação ao serviço de saúde. No entanto, não havia uma orientação sistematizada quanto ao tipo de informações que seriam de relevância para o trabalho e, portanto, esta definição dependia da forma como cada ACS compreendia a relação entre o processo saúde-doença e os acontecimentos e condições de vida da população. Não tendo sido previamente estimulados a refletir e a exercitar formas de sistematizar as visitas, os ACS tendiam à reprodução mecânica do registro das situações encontradas durante suas visitas, utilizando terminologias desgastadas e empobrecidas, sendo comum, por exemplo, o uso da expressão "tudo bem" para o registro de uma visita durante a qual não tivesse sido trazida ou discutida alguma condição de doença ou problema patológico.

Havia o entendimento de que não se tratava de definir mais um pacote de informações a serem colhidas pelos ACS. A equipe da unidade de saúde havia identificado a necessidade de se manter uma relação pedagógica sistemática entre todos os profissionais e destes com a comunidade, de maneira a permitir a construção compartilhada do conhecimento. Entendia-se que os agentes de saúde eram capazes de identificar situações e condições que não chegavam ao posto de saúde, mas que era preciso aperfeiçoar a organização do registro de informações.

Tendo a educação popular e saúde como referência metodológica (Stotz et al., 2005) e o conceito de ambientação pedagógica como norteador da prática educativa em serviço (Núcleo de Estudos Locais em Saúde, 1997), foram organizados vários encontros que culminariam com a construção de um roteiro para registro das informações.

Ambientação pedagógica é um conceito que se refere ao reconhecimento dos serviços e ações de saúde como espaço de construção coletiva e de aprendizado compartilhado sobre a realidade de saúde local, e para o desenho de alternativas para enfrentar os problemas e questões identificados. Constitui uma práxis perpassada pela educação problematizadora e supõe um sistema local de informação que envolva a comunidade. Desenvolveu-se durante a experiência do Elos com o Programa de Residência Coletiva da Escola Nacional de Saúde Pública. Entendido como o esforço para superar a fragmentação de saberes e processos de trabalho no nível local, corresponde a uma formação continuada efetivamente interativa com a comunidade e suas necessidades de saúde, e aproxima-se do que, posteriormente, consolidou-se no conceito de educação permanente (Ceccim, 2005). 
Foram realizados vários encontros com o grupo de agentes de saúde partindo da proposta pedagógica de Paulo Freire $(1993,1970)$, na qual a problematização da realidade representa o ponto de partida para o processo de aprendizagem, tanto por despertar no educando o desejo do conhecimento, como por possibilitar a continuidade do processo de aprendizagem com a apropriação de novas ideias e conceitos. A reflexão crítica com base nas experiências anteriores deveria ser também uma fonte estimuladora de autonomia e decisão frente a situações-limite vivenciadas no cotidiano do trabalho. A problematização da realidade é, assim, mais que um método educativo, um processo de construção dialógica de conhecimentos, confrontados e compartilhados, que provoca os sujeitos a trazerem suas perspectivas e olhares na descrição e explicação de situações para as quais as respostas não estão imediatamente disponíveis.

Buscava-se partir da experiência dos agentes comunitários, como moradores da comunidade e como profissionais de saúde, e, junto com eles, identificar os fatores relevantes para a construção de indicadores baseados em um conceito crítico de risco que orientasse a priorização de suas atividades. Os passos desenvolvidos durante os encontros incluíram o levantamento exaustivo de problemas encontrados durante as visitas domiciliares, mediante a livre expressão de ideias pelas participantes e a narrativa por escrito de casos familiares típicos, baseados nas experiências com os moradores da área.

O levantamento de problemas deu-se por meio de círculos de debates com os ACS, alternados com discussões em grupos menores, mediados pelos pesquisadores do Elos e por profissionais do posto de saúde, cuja participação tinha dois objetivos: facilitar e provocar a participação de todos os ACS no debate e sistematizar de forma escrita este processo, com a devolução e o confronto das interpretações elaboradas para verificação, apurando-se, no decorrer das oficinas, um conjunto de problemas categorizados segundo sua natureza. O processo de categorização manteve certa aderência aos conceitos já utilizados nas abordagens programáticas da saúde, recuperando categorias como "problemas ambientais" ou "problemas de saúde mental", mas abrindo-se a possibilidade de inclusão de questões referentes ao contexto local, cuja identificação e compreensão dependiam do conhecimento prático das ACS, construído na atividade de trabalho.

Um dos casos relatava a situação de uma família de sete pessoas. A frente da casa era um ferrovelho que se expandia para dentro da moradia. O chão era de terra e havia ratos e baratas. Devido à sujeira, um bebê de oito meses ficava o dia todo no carrinho, pois não podia ser colocado no chão. $O$ dono da casa era alcoólatra, passava mais tempo bêbado do que sóbrio. Ninguém na casa trabalhava. Dois meninos, de nove e onze anos, não estavam estudando porque, segundo a mãe, fugiam constantemente da escola. A filha de dezenove anos já era mãe de dois filhos. A mãe estava triste e deprimida por causa dos problemas. Esta é uma situação que dificilmente seria apreendida na unidade de saúde durante a consulta de algum integrante da família, e nesse sentido o registro feito pela ACS era fundamental para que a equipe entendesse o quadro.

Em outro momento, evidenciou-se a importância de se discutirem as condições de vida impostas à população como uma questão que não se dissocia do processo de trabalho do ACS e da equipe. A grandeza da problemática, a falta de perspectiva da população, a presença limitada do Estado, tanto em termos de resposta por parte dos serviços, como em relação ao cumprimento justo das regras estabelecidas pela sociedade, sufocam aqueles que lidam com a situação. O sofrimento vivenciado pelas ACS, originado nestas percepções, foi por elas expressado em uma das atividades de avaliação, já que, muitas vezes, sentiam-se sobrecarregadas com a problemática abordada durante as visitas domiciliares. Como disse uma ACS, referindo-se ao seu trabalho: "Ouvir faz bem às pessoas, desabafam...". Mas, por outro lado, o ACS envolve-se nas situações, leva problemas dos clientes para casa, como expressou nesta outra fala: "Está lavando a louça e lembra de um problema, sonha com os problemas dos clientes. ACS deveria ter acesso a psicólogo".

Após as oficinas de levantamento de questões, passou-se à sistematização dos problemas registrados. Com base no saber experiente das agentes de saúde e no saber técnico dos especialistas envolvidos, foram surgindo propostas para a classificação dos riscos encontrados. Como resultado desta atividade, foi elaborada uma "tabela de riscos", relacionados ao meio, à habitação, às condições de vida da família, ao modo de vida dos componentes da família, e à relação com os serviços de saúde. 
O processo terminou com a construção do roteiro para registro de informação, com base nos procedimentos anteriores. O objetivo do roteiro era guiar a observação da realidade vivenciada pela população e facilitar sua sistematização, por meio do registro de problemas que poderiam ser relevantes para o trabalho em saúde e que não estavam previstos nos formulários do SIAB. O roteiro contemplava informações relativas aos indivíduos, família, moradia, ambiente da comunidade e serviços de saúde.

Em seguida à construção do roteiro, foi realizada uma oficina com as agentes de saúde, em que foram relatados casos que haviam sido observados nas visitas domiciliares e nos quais o roteiro tinha servido como instrumento norteador das anotações. Situações complexas de famílias com problemas relacionados ao alcoolismo, violência doméstica ou suspeita de doenças, que não apareceriam em um registro que levasse em conta somente o formulário do SIAB, foram registrados nas anotações das agentes. Os relatos de caso possibilitaram o exercício de elaboração de textos e, ao mesmo tempo, permitiram a discussão dos fatores envolvidos em cada situação. O novo instrumento de registro das visitas domiciliares foi aprovado nesta oficina e agregado à rotina de trabalho das agentes, para os casos em que as ACS percebessem que a ficha de cadastro do SIAB não contemplasse as necessidades de registro de uma determinada situação.

Os problemas levantados durante os encontros continham, em grande parte, situações que interferem na saúde dos indivíduos e da família, mas que, na maioria das vezes, estão fora do âmbito de resolução dos serviços de saúde e apresentam-se como questões para as quais não estão disponíveis respostas imediatas, situações-limite (Freire, 1970). Segundo uma agente de saúde, "existem muitas situações em que a população pede ajuda ao ACS, mas este não pode fazer nada. Às vezes não tem a ver com saúde." Nesse sentido, procurando não incidir no reducionismo do risco focal, buscou-se um critério classificatório para as diversas situações que pudessem orientar a ação dos ACS. Seria possível concluir que os problemas das famílias podem ser classificados segundo três níveis de intervenção: a) problemas passíveis de resolução com os meios disponíveis no serviço de saúde; b) problemas passíveis de resolução com os meios disponíveis na comunidade, dependendo de ação intersetorial; c) problemas não solucionáveis no nível local, que dependem de articulações externas ou mesmo de políticas públicas.

\section{Conclusão}

A atividade educativa desenvolvida com as ACS permitiu a organização de percepções sobre a complexidade do cotidiano da população, também vivenciado pelas próprias agentes enquanto moradoras da comunidade, e sobre as limitações de lidar com a problemática das famílias de maneira focalizada. O conceito de risco, reconfigurado a partir da percepção coletiva e da leitura das condições concretas de produção e reprodução da vida (Freire, 1970), é apropriado pelos ACS como ferramenta conceitual orientadora de sua atividade de trabalho. Desloca-se o peso do processo decisório sobre o que fazer com as situações identificadas, uma vez que, na reflexão-ação, em lugar de restringir-se a nomeá-las como "de risco", os ACS já vão apontando as saídas e estratégias para enfrentá-las.

Na perspectiva da educação popular e saúde, no entanto, a saída é coletiva (Stotz et al., 2005; Freire, 1993, 1970). Referindo-se à pobreza, Santos (1979, p.10) menciona que "o assunto exige um tratamento dinâmico, no qual todo o conjunto de fatores é levado em conta - pois do contrário haverá ênfase em soluções parciais que são mutuamente contraditórias". Alerta ainda para a importância de que também o processo de análise se dê em bases coletivas, em uma estrutura analítica que considere o contexto concreto onde se produzem as questões em foco.

O conceito de risco construído é, assim, dinâmico, e se desenvolve a partir do compartilhamento de saberes e do desvelamento das múltiplas relações que os diversos problemas estabelecem com o contexto local e global (Carvalho, Accioli, Stotz, 2001). Do ponto de vista do trabalho das ACS, espera-se que as expectativas destas agentes com relação à resolubilidade do seu trabalho adquiram maior racionalidade em relação à sua efetividade operacional, na medida em que se aprofunda a compreensão sobre o contexto dos problemas encontrados. 
A problematização de situações-limite recoloca a questão da arbitragem social (Mitjavila, 2002), no sentido de indagar a quem cabe dar respostas para estas situações, e evidencia quão limitado é intervir com base apenas em uma compreensão individualizada sobre risco. Esta compreensão individualizada transparece na orientação dada ao ACS para visitar (ou vigiar?) sobretudo as chamadas "famílias de risco". Na perspectiva crítica da educação popular, entende-se o processo educativo como a própria construção, também coletiva, da resposta possível, do inédito-viável (Carvalho, Accioli, Stotz, 2001; Freire, 1970).

A capacidade de estabelecer laços orgânicos no apoio às estratégias de enfrentamento das situações vivenciadas pela população, e com a organização política de sua comunidade, aliados ao seu potencial engajamento em práticas e movimentos sociais, evidenciam a importância do ACS como ator fundamental para o avanço da mudança desejada, direcionada para um modelo assistencial capaz de contemplar a equidade, a integralidade, a humanização e a participação popular.

\section{Colaboradores}

Os autores trabalharam juntos em todas as etapas de produção do manuscrito.

\section{Referências}

ARAÚJO, J.W.G. Saúde pública, epidemiologia e senso comum: epidemia de meningite como evento social. 2004. Tese (Doutorado) - Escola Nacional de Saúde Pública, Fundação Oswaldo Cruz, Rio de Janeiro. 2004.

BACHELARD, G. O novo espírito científico. Rio de Janeiro: Tempo Brasileiro, 1985.

BRASIL. Ministério da Saúde. Portaria n.648, de 28 de março de 2006. Dispõe sobre a aprovação da Política Nacional de Atenção Básica, estabelecendo a revisão de diretrizes e normas para a organização da Atenção Básica para o Programa Saúde da Família e o Programa Agentes Comunitários de Saúde. Diário Oficial da União, Brasília, DF, n.61, seção 1, p.71, 29 mar. 2006.

. Ministério da Saúde. Ministério da Educação. Referencial curricular para curso técnico de agente comunitário de saúde: área profissional saúde. Brasília, 2004. Disponível em: <http://bvsms.saude.gov.br/bvs/publicacoes/referencial_Curricular_ACS. pdf $>$. Acesso em: 22 maio 2007.

CAPONI, S. A saúde como abertura ao risco. In: CZERESNIA, D.; FREITAS, C.M. (Orgs.). Promoção da saúde: conceitos, reflexões, tendência. Rio de Janeiro: Fiocruz, 2003. p.5577.

CARVALHO, M.A.P.; ACIOLI, S.; STOTZ, E.N. O processo de construção compartilhada do conhecimento: uma experiência de investigação científica do ponto de vista popular. In: VASCONCELOS, E.M. (Org.). A saúde nas palavras e nos gestos: reflexões da rede de educação popular e saúde. São Paulo: Hucitec, 2001. p.101-14.

CASTIEL, L.D. Metáforas para uma epidemiologia mestiça. In: ALMEIDA FILHO, N. et al. (Orgs.). Teoria epidemiológica hoje: fundamentos, interfaces e tendências. Rio de Janeiro: Fiocruz, 1998. p.225-55.

CECCIM, R.B. Educação permanente em saúde: desafio ambicioso e necessário. Interface - Comunic., Saude, Educ., v.9, n.16, p.161-8, 2005. 
ELOS. NÚCLEO DE ESTUDOS LOCAIS EM SAÚDE. Escola Nacional de Saúde Pública. Investigação, ensino, serviços de saúde e sociedade civil: uma proposta de construção compartilhada do conhecimento no nível local. Relatório de atividades: biênio 1995-1996. Rio de Janeiro: Fiocruz, 1997. (Mimeogr.)

FREIRE, P. Política e educação: ensaios. São Paulo: Cortez, 1993.

Pedagogia do oprimido. Rio de Janeiro: Paz e Terra, 1970.

LUPTON, D. Risk. London: Routledge, 1999.

MEHRY, E.E. Em busca do tempo perdido: a micropolítica do trabalho vivo em saúde. In: MEHRY, E.E.; ONOCKO, R. (Orgs.). Agir em saúde: um desafio para o público. São Paulo: Hucitec, 1997. p.71-112.

MITJAVILA, M. O risco como recurso para a arbitragem social. Tempo Soc., v.14, n.2, p.129-45, 2002.

NUNES, E.D. Saúde coletiva: história e paradigmas. Interface - Comunic., Saude, Educ., v.3, p.106-16, 1998

SANTOS, M. Pobreza urbana. São Paulo: Hucitec, 1979.

STOTZ, E.N.; DAVID, H.M.S.L.; WONG UN, J.A. Educação popular e saúde: trajetória, expressões e desafios de um movimento social. Rev. APS, v.8, n.1, p.49-60, 2005.

TELLES, V.S. A "nova questão social" brasileira: ou como as figuras de nosso atraso viraram símbolo de modernidade. In: (Org.). Pobreza e cidadania. São Paulo: Ed. 34, 2001. p.139-65.

VALLA, V.V. A construção desigual do conhecimento e o controle social dos serviços públicos de educação e saúde. In: VALLA, V.V.; STOTZ, E.N. (Orgs.). Participação popular, educação e saúde: teoria e prática. Rio de Janeiro: Relume Dumará, 1993. p.43-56.

VASCONCELOS, E.M. A priorização da família nas políticas de saúde. Saúde em Debate, v.23, n.53, p.6-19, 1999.

BORNSTEIN, V.J.; DAVID, H.M.S.L.; ARAÚJO, J.W.G. Agentes comunitarios de salud: la reconstrucción del concepto de riesgo a nivel local. Interface - Comunic., Saude, Educ. v.14, n.32, p.93-101, jan./mar. 2010.

Se discute el concepto de riesgo y sus límites como constructivo técnico-científico de representación de la realidad y dispositivo de apoyo a la intervención social. La evolución histórica de la epidemiología y del concepto de riesgo se relaciona a la idea de arbitraje social junto a los grupos populacionales, examinándose la posibilidad de apropiación de este concepto para la ampliación de la percepción y el fortalecimiento de las respuestas sociales a las situaciones de salud y vida, a la luz de una experiencia pedagógica basada en la perspectiva de la educación popular y de la salud con agentes comunitarios de salud de una localidad urbana periférica. Se defiende que los procesos educativos participativos amplían la participación de saberes y la capacidad de analizar críticamente las múltiples relaciones entre los problemas de salud y los contextos de vida local y global, recolocando la cuestión del arbitraje social en las respuestas a las situaciones límite.

Palabras clave: Agentes comunitarios de salud. Formación de concepto. Educación en salud. Riesgo. 